\title{
Techniques for Avoiding Saccular Extended Obstruction at the Anastomotic Site of Functional End-to-End Anastomosis
}

\author{
Koichi Yoshida, Kenichi Ietsugu, Jyunpei Okamoto, Saki Hayashi, Yoshihide Asaumi, \\ Naohiro Ota, Hiroyuki Sugawara, Satoshi Tabata, Masahiro Kaneki, Mitsuaki Sakatoku, \\ Kaoru Kiyohara
}

Department of Surgery, Tonami General Hospital, Toyama, Japan

Email:kouichiyojp@yahoo.co.jp

How to cite this paper: Yoshida, K., Ietsugu, K., Okamoto, J., Hayashi, S., Asaumi, Y., Ota, N., Sugawara, H., Tabata, S., Kaneki, M., Sakatoku, M. and Kiyohara, K. (2017) Techniques for Avoiding Saccular Extended Obstruction at the Anastomotic Site of Functional End-to-End Anastomosis. Surgical Science, 8, 305-311.

https://doi.org/10.4236/ss.2017.87033

Received: June 14, 2017

Accepted: July 15, 2017

Published: July 18, 2017

Copyright (C) 2017 by authors and Scientific Research Publishing Inc. This work is licensed under the Creative Commons Attribution International License (CC BY 4.0).

http://creativecommons.org/licenses/by/4.0/

\section{(c) (i) Open Access}

\begin{abstract}
Saccular extended obstruction is generated when the anastomotic site of functional end-to-end anastomosis is extended saccularly and blocked by intestinal contents. This is a specific complication of functional end-to-end anastomosis. Saccular extended obstruction of the anastomotic site of functional end-to-end anastomosis causes postoperative intestinal obstruction. Saccular extended obstruction places a heavy burden on patients because surgery is necessary for treatment of intestinal obstruction due to saccular extended obstruction. However, saccular extended obstruction is not a commonly recognized complication. The greatest factor contributing to the development of saccular extended obstruction is an acute angle between the portions of the intestinal tract oral and aboral to the anastomotic site. When this angle approaches obtuse angle, preferably close to a straight line, stagnation of the intestinal contents does not occur at the anastomotic site of functional end-to-end anastomosis and saccular extended obstruction is avoided. For making the angle of anastomotic intestinal tracts obtuse or straight, it may be effective that the entry hole of stapling suture instrument creating the anastomotic stoma is closed perpendicular to the intestinal axis.
\end{abstract}

\section{Keywords}

Functional End-to-End Anastomosis, Stapling Anastomosis, Anastomosis, Postoperative Complication, Intestinal Obstruction

\section{Introduction}

Functional end-to-end anastomosis (FEEA) has gained popularity as an easily performed stapling anastomosis technique. In rare cases, however, the anasto- 
motic site of FEEA is extended saccularly because of stagnation of intestinal contents and becomes blocked. We use the term saccular extended obstruction (SEO) to describe this obstruction of the anastomotic site of FEEA. SEO is a specific complication of FEEA and a cause of postoperative intestinal obstruction. However, SEO is not a commonly recognized complication because few reports relevant to this complication have been published. SEO places a heavy burden on patients because surgery is necessary for treatment of intestinal obstruction due to SEO. Therefore, SEO must be given sufficient attention to avoid its development. We herein report the pathogenesis of SEO and techniques for avoiding SEO at the anastomotic site of FEEA. This report is a clinical investigation in our institution.

\section{SEO}

\subsection{Pathogenesis of SEO}

When the angle between the portions of the intestinal tract oral and aboral to the anastomotic site is acute, flow of intestinal contents folds backward and stagnation of these intestinal contents make the anastomotic site expanded saccularly. This saccular extended anastomotic site of FEEA generates a relative stenosis of the portion of the intestinal tract aboral to the anastomotic site, eventually leading to intestinal obstruction (Figure 1 and Figure 2).

\subsection{Notes of Caution for the Avoidance of SEO}

The principle for prevention of SEO is avoidance of stagnation of intestinal contents. Thus, it is important that the angle between the portions of the intestinal tract oral and aboral to the anastomotic site is obtuse angle, preferably close to a straight linefor the avoidance of SEO. In addition, a larger anastomotic stoma of FEEA is associated with poorer clearance of the anastomotic site when the angle between the two portions of the intestinal tract is acute (Figure 3 ).

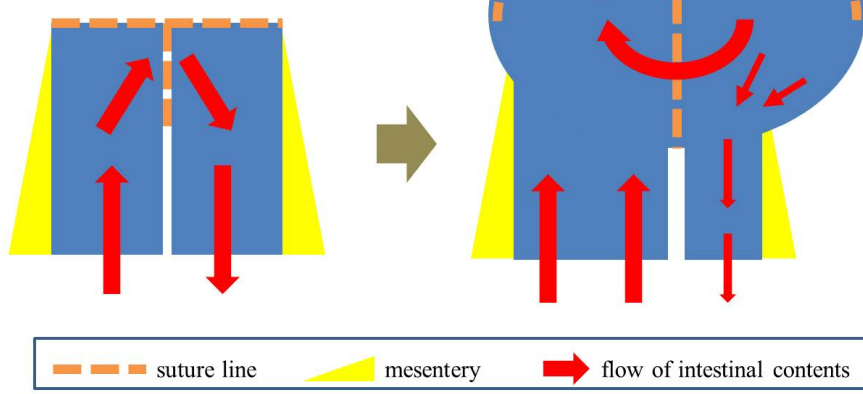

Figure 1. The saccular extended anastomotic site of FEEA generates a relative stenosis of the aboral intestinal tract. This relative stenosis leads to an intestinal obstruction of the aboral intestinal tract. 


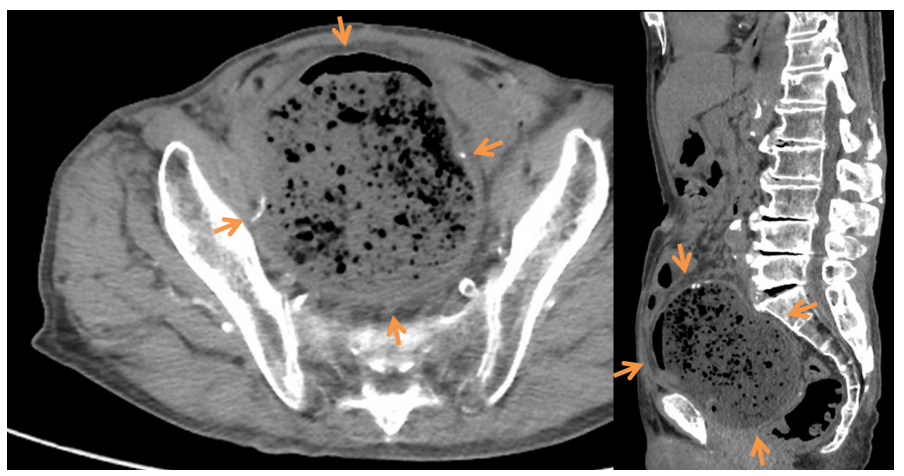

Figure 2. Our case of SEO. The anastomotic site is extended saccularly due to stagnation of the intestinal contents and has become blocked (arrows).

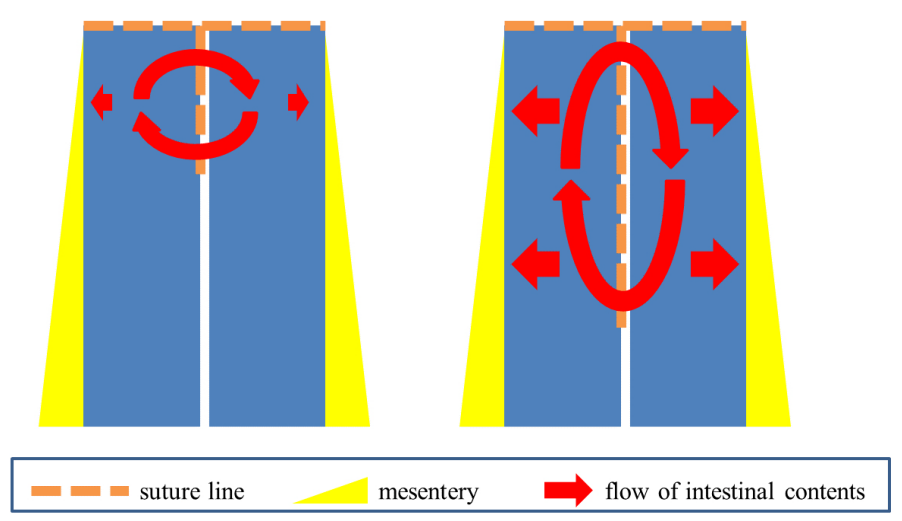

Figure 3. A larger anastomotic stoma of FEEA is associated with poorer clearance of the anastomotic site.

\section{Surgical Techniques for Avoiding SEO}

Various methods of FEEA are available. Basically, the anastomotic stoma is created using a stapling suture instrument on the other side of the mesentery, the entry hole is closed with the stapling suture instrument, and the FEEA is completed. Closure of the entry hole is important for avoiding SEO. When the entry hole is closed in parallel with the intestinal axis, the angle between the portions of the intestinal tract oral and aboral to the anastomosis tends to become acute (Figure 4). However, if the entry hole is closed perpendicular to the intestinal axis, the angle between the two portions of the intestinal tract becomes more obtuse or straight (Figure 5). An obtuse angle or straight line is important for avoiding SEO. Additionally, Lembert suture on the stapler line of the entry hole and closing or pulling the mesentery are also effective in making this angle more obtuse or straight (Figure 6 and Figure 7).

\section{Results in Our Institution}

We have performed FEEA with these techniques since 2010. We have not experienced SEO on the anastomotic site of FEEA since introducing these techniques. We summarized the patients who received FEEA over the last two years, between April 2015 and March 2017 (Table 1). 89 patients had received FEEA. The 


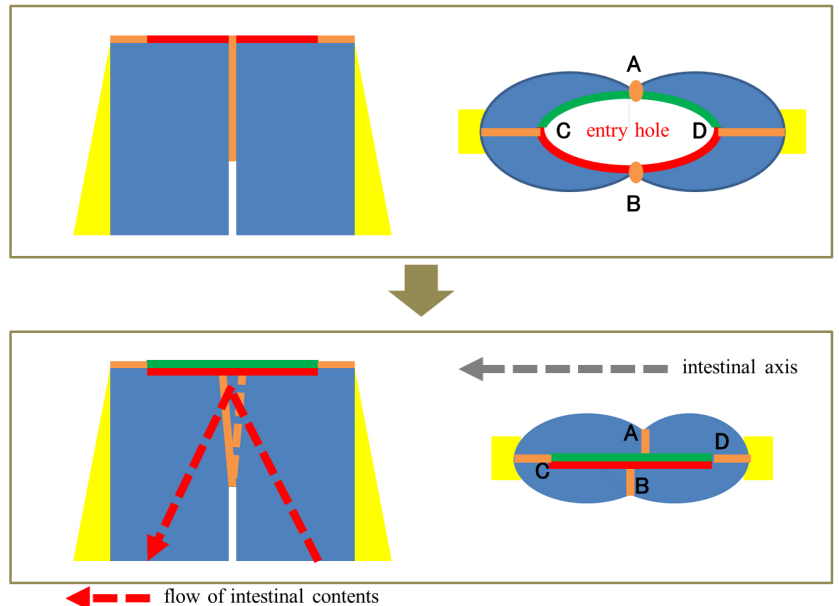

Figure 4. When the entry hole is closed in parallel with the intestinal axis, the angle between the portions of the intestinal tract oral and aboral to the anastomosis becomes acute.

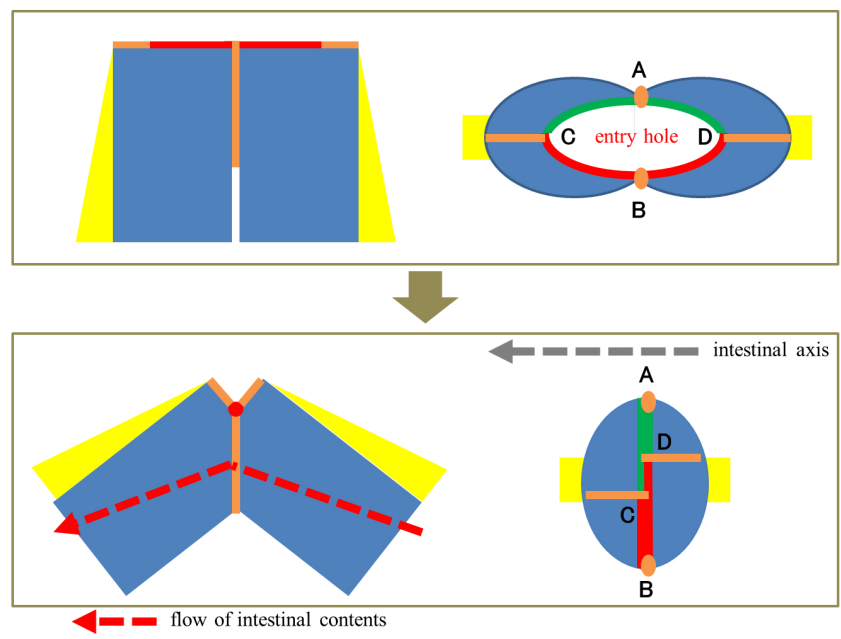

Figure 5. When the entry hole is closed perpendicular to the intestinal axis, the angle between the two portions of the intestinal tract becomes more obtuse or straight.

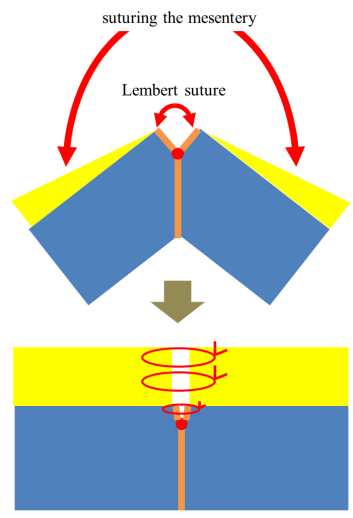

Figure 6. Lembert suture on the staple line of the entry hole and suturing the mesentery are also effective in making this angle more obtuse or straight. 


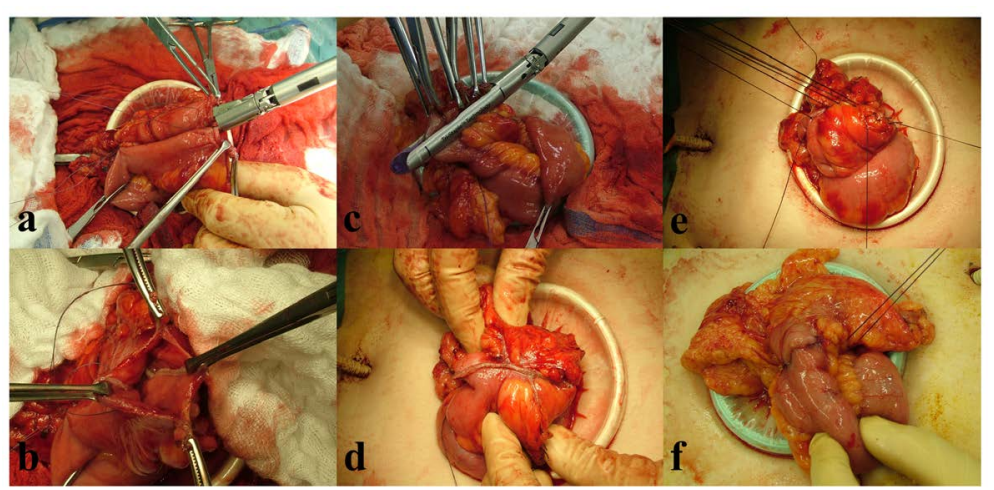

Figure 7. Actual intraoperative photographs. (a) (b) An anastomotic stoma is created using a stapling suture instrument on the other side of the mesentery; (c) (d) The entry hole is closed perpendicular to the intestinal axis with the stapling suture instrument; (e) Lembert suture is placed on the staple line of the entry hole; and (f) a few sutures are placed on the mesentery near the intestinal tract.

Table 1. Summary of FEEA on our institution during the last 2 years (April 2015-March 2017).

\begin{tabular}{|c|c|}
\hline Variable & Data \\
\hline Number of patients, $\mathrm{n}$ & 89 \\
\hline \multicolumn{2}{|l|}{ Gender, $\mathrm{n}$} \\
\hline Male & 48 \\
\hline Female & 41 \\
\hline Age, mean \pm SD (range), y & $73.1 \pm 12.3(30-93)$ \\
\hline \multicolumn{2}{|l|}{ Primary disease, $\mathrm{n}$} \\
\hline Colonic cancer & 52 \\
\hline Intestinal obstruction & 13 \\
\hline Stoma closure & 11 \\
\hline Others & 13 \\
\hline \multicolumn{2}{|l|}{ Approach, $n$} \\
\hline Laparoscopic & 48 \\
\hline Open & 41 \\
\hline Emergency, $\mathrm{n}$ & 18 \\
\hline \multicolumn{2}{|l|}{ Anastomosis, $\mathrm{n}$} \\
\hline Small intestine-large intestine & 59 \\
\hline Small intestine-small intestine & 25 \\
\hline Large intestine-large intestine & 5 \\
\hline \multicolumn{2}{|c|}{ Postoperative complication related to the anastomotic site, $\mathrm{n}$} \\
\hline Intestinal obstruction & 0 \\
\hline Leakage & 0 \\
\hline Others & 0 \\
\hline
\end{tabular}


anastomosis between the small intestine and the large intestine was majority and was performed in 59 patients. Postoperative complication related to the anastomotic site was none.

\section{Discussion}

FEEA was first reported by Steichen in 1968, and today it is a standard stapling anastomosis method [1]. Factors that have helped FEEA to become more widespread include its convenience and association with few complications. In Japan, however, a few reports of intestinal obstruction due to saccular extension of the anastomotic site of FEEA with blockage by intestinal contents have been published in recent years [2] [3] [4]. Because only a few reports are available, an official term for this condition has not been established. Therefore, we have termed this complication SEO in the present report. The greatest factor contributing to the development of SEO is an acute angle between the portions of the intestinal tract oral and aboral to the anastomotic site. When this angle approaches a straight line, stagnation of the intestinal contents does not occur at the anastomotic site of FEEA, and SEO is avoided.

Generally, FEEA may be performed with the techniques based on procedure reported by Steichen [1]. However, the entry hole of stapling suture instrument creating the anastomotic stoma is closed in parallel with the intestinal axis in that procedure, so this angle is an acute angle. In order to make this angle obtuse or straight, we consider that it may be effective that the entry hole is closed perpendicular to the intestinal axis.

Recently many surgeons may not perform suture closure of the mesentery of the reconstructed intestinal tract. However, pulling this mesentery helps to linearize the reconstructed intestinal tract. Therefore, we recommend placing a few sutures in the mesentery near the intestinal tract.

SEO develops by deformation of the anastomotic portion over a long period of several months to several years postoperatively. In principle, surgical treatment of SEO is required because conservative treatment cannot guarantee improvement of the deformation that forms during this chronic course [3] [4]. There was also a report that intestinal perforation has developed from the anastomotic site expanded with SEO [4]. We had experienced a case of SEO that required surgical treatment. We performed a bypass between the portions of the intestinal tract oral and aboral to the anastomotic site. Because the anastomotic site of FEEA extended saccularly was strongly adhered to the back of the pubic bone, we abandoned a resection of the anastomotic site and reanastomosis. The need for surgical repair of SEO places a heavy burden on patients. Therefore, it is important to take measures to avoid SEO.

We have performed the FEEA by this reported technique since 2010 and have not experienced SEO since introducing these techniques. We recommend that the entry hole is closed perpendicular to the intestinal axis and Lembert suture on the stapler line of the entry hole and placing a few sutures in the mesentery near the intestinal tract are performed. 


\section{References}

[1] Steichen, F.M. (1968) The Use of Stapler in Anatomical Side-to-Side and Functional End-to-End Enteroanastomoses. Surgery, 64, 948-953.

[2] Negami, N., Satou, M., Watanabe, S., Saitou, T., Ishido, Y. and Yamada, M. (2010) A Case of Fecal Ileus Caused by Fecal Impaction in the Intestine at the Anal Side of a Functional End-to-End Anastomotic Site. Journal of Japan Surgical Association, 71, 1216-1221. https://doi.org/10.3919/jjsa.71.1216

[3] Sato, Y., Kuroki, Y., Kudo, H. and Hayashi, H. (2015) A Case of Blind Loop Syndeome in the Functional End-to-End Anastomotic Site of Laparoscopic Surgery. Journal of Japan Surgical Association, 76, 2735-2739.

https://doi.org/10.3919/jjsa.76.2735

[4] Toyosaki, R., Kanmura, M., Oyama, T., Mita, T., Sato, R. and Kitazono, M. (2015) A Case of Perforation Cause by Accumulation of Feces at the Site of a Functional Endto-End Anastomosis after Laparoscopy Assisted Transvers Colectomy. Journal of Japan Surgical Association, 76, 3029-3033. https://doi.org/10.3919/jjsa.76.3029

\section{Scientific Research Publishing}

Submit or recommend next manuscript to SCIRP and we will provide best service for you:

Accepting pre-submission inquiries through Email, Facebook, LinkedIn, Twitter, etc. A wide selection of journals (inclusive of 9 subjects, more than 200 journals)

Providing 24-hour high-quality service

User-friendly online submission system

Fair and swift peer-review system

Efficient typesetting and proofreading procedure

Display of the result of downloads and visits, as well as the number of cited articles

Maximum dissemination of your research work

Submit your manuscript at: http://papersubmission.scirp.org/

Or contact ss@scirp.org 